\title{
Night of the hunter: Using cameras to quantify nocturnal activity in desert spiders
}

\author{
Tamara I Potter ${ }^{\text {Corresp., 1, 2 }, \text { Aaron C Greenville }}{ }^{2,3}$, Christopher R Dickman ${ }^{2,3}$ \\ ${ }^{1}$ Terrestrial Ecosystem Research Network, School of Biological Sciences, University of Adelaide, Adelaide, South Australia, Australia \\ 2 Desert Ecology Research Group, School of Life and Environmental Sciences, University of Sydney, Sydney, New South Wales, Australia \\ 3 National Environmental Science Program Threatened Species Recovery Hub, School of Life and Environmental Sciences, University of Sydney, Sydney, \\ New South Wales, Australia \\ Corresponding Author: Tamara I Potter \\ Email address: tamara.potter@adelaide.edu.au
}

Invertebrates dominate the animal world in terms of abundance, diversity and biomass, and play critical roles in maintaining ecosystem function. Despite their obvious importance, disproportionate research attention remains focused on vertebrates, with knowledge and understanding of invertebrate ecology still lacking. Due to their inherent advantages, usage of camera traps in ecology has risen dramatically over the last three decades, especially for research on mammals. However, few studies have used cameras to reliably detect fauna such as invertebrates or used cameras to examine specific aspects of invertebrate ecology. Previous research investigating the interaction between wolf spiders (Lycosidae: Lycosa spp.) and the lesser hairy-footed dunnart (Sminthopsis youngsoni) found that camera traps provide a viable method for examining temporal activity patterns and interactions between these species. Here, we re-examine lycosid activity to determine whether these patterns vary with different environmental conditions, specifically between burned and unburned habitats and the crests and bases of sand dunes, and whether cameras are able to detect other invertebrate fauna. Twenty-four cameras were deployed over a 3-month period in an arid region in central Australia, capturing 2,356 confirmed images of 7 invertebrate taxa, including 155 time-lapse images of lycosids. Overall, there was no clear difference in temporal activity with respect to dune position or fire history, but twice as many lycosids were detected in unburned compared to burned areas. Despite some limitations, camera traps appear to have considerable utility as a tool for determining the diel activity patterns and habitat use of larger arthropods such as wolf spiders, and we recommend greater uptake in their usage in future. 
1 Night of the hunter: using cameras to quantify 2 nocturnal activity in desert spiders

3

4

5

6

7

8

\author{
Tamara I. Potter ${ }^{1,2}$, Aaron C. Greenville ${ }^{2,3}$ and Christopher R. Dickman ${ }^{2,3}$ \\ ${ }^{1}$ Terrestrial Ecosystem Research Network, School of Biological Sciences, University of Adelaide, \\ Adelaide, SA 5005, Australia \\ ${ }^{2}$ Desert Ecology Research Group, School of Life and Environmental Sciences, University of \\ Sydney, NSW 2006, Australia \\ ${ }^{3}$ National Environmental Science Program Threatened Species Recovery Hub, School of Life and \\ Environmental Sciences, University of Sydney, NSW 2006, Australia \\ Corresponding Author: \\ Tamara Potter ${ }^{1}$ \\ GPO Box 498, Adelaide, South Australia, 5005, Australia \\ Email address: tamara.potter@adelaide.edu.au
}


18

19

20

21

22

23

24

25

26

27

28

29

30

31

32

33

34

35

36

37

38

39

40

41

42

43

44

45

46

47

48

49

50

51

52

53

54

55

56

57

58

59

60

61

62

\section{Abstract}

Invertebrates dominate the animal world in terms of abundance, diversity and biomass, and play critical roles in maintaining ecosystem function. Despite their obvious importance, disproportionate research attention remains focused on vertebrates, with knowledge and understanding of invertebrate ecology still lacking. Due to their inherent advantages, usage of camera traps in ecology has risen dramatically over the last three decades, especially for research on mammals. However, few studies have used cameras to reliably detect fauna such as invertebrates or used cameras to examine specific aspects of invertebrate ecology. Previous research investigating the interaction between wolf spiders (Lycosidae: Lycosa spp.) and the lesser hairy-footed dunnart (Sminthopsis youngsoni) found that camera traps provide a viable method for examining temporal activity patterns and interactions between these species. Here, we re-examine lycosid activity to determine whether these patterns vary with different environmental conditions, specifically between burned and unburned habitats and the crests and bases of sand dunes, and whether cameras are able to detect other invertebrate fauna. Twenty-four cameras were deployed over a 3-month period in an arid region in central Australia, capturing 2,356 confirmed images of 7 invertebrate taxa, including 155 time-lapse images of lycosids. Overall, there was no clear difference in temporal activity with respect to dune position or fire history, but twice as many lycosids were detected in unburned compared to burned areas. Despite some limitations, camera traps appear to have considerable utility as a tool for determining the diel activity patterns and habitat use of larger arthropods such as wolf spiders, and we recommend greater uptake in their usage in future.

\section{Introduction}

Invertebrates dominate the world's animal biota in terms of abundance, diversity and biomass (Black et al. 2001; Ellwood \& Foster 2004; McCollough 1997). They play a critical role in maintaining ecosystem function by performing basic services such as energy and nutrient cycling, pollination, herbivory and seed dispersal (Black et al. 2001; Freckman et al. 1997; Oberprieler et al. 2019). Some invertebrates are also keystone species and are fundamental in regulating the structure of biotic communities (Black et al. 2001). However, despite their obvious ecological importance, there is a disproportionate focus in many areas of research on vertebrates, with a clear disparity in regards to our knowledge and understanding of the ecology of invertebrate fauna (Oberprieler et al. 2019; Ponder \& Lunney 1999).

Many methods are employed to sample terrestrial invertebrates. These can be either direct or indirect, and vary depending on the aims of the study, the habitat and often the habits of the taxa being sampled. For instance, one of the most common methods to efficiently sample grounddwelling invertebrates is the wet pitfall trap (Callan et al. 2011; Gist \& Crossley 1973; Potter et al. 2018). Invertebrates can also be collected as by-catch from vertebrate pitfall traps (Oberprieler et al. 2019; Potter et al. 2018; Woinarski et al. 2002), while netting, vacuuming and beating of plant leaves and fronds are used to sample invertebrates that live within vegetation (Callan et al. 2011; Popic et al. 2013; Southwood \& Henderson 2000). Other methods include hand netting and pan traps for aerial invertebrates (Popic et al. 2013), raking leaf litter (Callan et al. 2011), fogging (for arthropods that dwell in the forest canopy; Ellwood \& Foster 2004), and diurnal or nocturnal hand searching and collecting (Callan et al. 2011; Gobbi et al. 2018; Potter et al. 2018). One of the key benefits of these approaches is that they collect actual animals, permitting detailed 
63 examination of morphology and providing material for genetic analyses, thus facilitating

64 taxonomic identification (Wong et al. 2019). These methods also allow information to be

65 gathered on abundance, diversity and population statistics (e.g., sex ratio or age class). One

66 prominent downside, however, is that these direct methods usually result in the death of

67 individuals captured and thus removes invertebrates from the study system. In comparison,

68 surveys of burrows or nests, tracks or other traces, and records of vocalisations, are examples of

69 non-invasive, indirect gauges of arthropod presence or activity that do not disrupt local population abundances (Henschel 2002; Nørgaard et al. 2006; Southwood \& Henderson 2000).

The use of remote-sensing camera traps has increased dramatically in the last three decades due

74

75

76 to the numerous advantages they provide in comparison with traditional sampling methods (Meek et al. 2015; Potter et al. 2019). While cameras are relatively non-invasive, collect information on numerous species, are convenient and cost-effective, their most valuable attribute is that they can monitor continuously over extended periods of time and can be utilised at a range of spatial scales (De Bondi et al. 2010; Harley et al. 2014). Cameras have been employed to observe cryptic fauna (Claridge et al. 2004; Nelson et al. 2014; Potter 2017), provide data to estimate occupancy and abundance (Gowan \& Vernes 2014; Rowcliffe et al. 2014), monitor animal behaviour (Vernes et al. 2014), and examine diel activity patterns (Diete et al. 2017; Meek et al. 2012). However, due to limitations regarding trigger mechanisms (e.g., heat or movement signatures), cameras have largely been used in research on large and small mammals, with fewer studies using cameras to detect birds, reptiles, amphibians and, especially, invertebrates (Agha et al. 2018; Collett \& Fisher 2017; Hobbs \& Brehme 2017; Lortie et al. 2012). Although the number of studies using cameras to monitor reptiles is on the rise (Bluett \& Cosentino 2013; e.g., Pagnucco et al. 2011; Welbourne et al. 2020), there are still very few researchers using this tool to explore any aspects of invertebrate ecology (Agha et al. 2018).

Previous research investigating the interaction between wolf spiders (Lycosidae: Lycosa spp.) and a small marsupial, the lesser hairy-footed dunnart (Sminthopsis youngsoni), resulted in the knowledge that 1) camera traps provide a viable method for detecting wolf spiders and 2) that captured images can be used to investigate temporal activity patterns and species interactions (Potter et al. 2017a; Potter et al. 2017b; Potter et al. 2017c; Potter et al. 2017d; Potter et al. 2018). Here, we re-examine lycosid activity to determine whether these patterns vary with different environmental conditions. Additionally, we extended our study to assess the capability of cameras to detect other invertebrate taxa. Our focus was primarily on lycosids as these active hunting spiders indicate the presence of diverse smaller invertebrates that form their major prey (Nyffeler \& Benz 1987) and because they are often selected as preferred prey by small vertebrate predators (Potter et al. 2018), and thus are important components of their constituent communities. Because of the ubiquity and importance of lycosids in trophic webs in many arid environments (Henschel 1998; Punzo 2003; Russell-Smith et al. 1987), we focused our sampling in the Simpson Desert of central Australia. To test the utility of cameras in distinguishing lycosid activity under different environmental conditions, we deployed camera traps on dune crests and dune bases (swale) in recently burned and unburned habitats. Owing to a high abundance of 
105

106

107

108

109

110

111

112

113

114

115

116

117

118

119

120

121

122

123

124

125

126

127

128

129

130

131

132

133

134

135

136

137

138

139

140

141

142

143

144

145

146

147

small, crepuscular marsupials in the study region that include spiders and other arthropods in their diet (Fisher \& Dickman 1993a; Fisher \& Dickman 1993b), we expected that lycosids would be less active near dawn and dusk in open habitats (dune crests and burned habitat) than in sheltered habitats (dune bases and unburned habitat) to reduce their risk of predation.

\section{Materials \& Methods Study site}

This study was undertaken over an area of $0.06 \mathrm{~km}^{2}$ near Main Camp, on Ethabuka Reserve (2346’ S, $138^{\circ} 28^{\prime}$ E), in the north-eastern Simpson Desert, Queensland, Australia, between July and October 2016. Access to the reserve was provided by Alex Kutt, Bush Heritage Australia Regional Ecologist, and Matt and Amanda Warr, the Reserve Managers, at the time of the study. The Simpson Desert is characterised by long, parallel sand dunes that run north-northwest to south-southeast, are 0.6-1 km apart and can be up to $10 \mathrm{~m}$ high (Dickman et al. 2010; Kwok et al. 2016; Purdie 1984). The dominant vegetation is spinifex (Triodia basedowii) grassland; however, the dune crests are sparsely covered in shrubs and other perennial species (Greenville et al. 2009; Kwok et al. 2016). Small stands of gidgee trees (Acacia georginae), mallee eucalypts

(Eucalyptus spp.) and other Acacia shrubs occur on the heavier clay soils of the interdune swales (Greenville et al. 2016; Kwok et al. 2016; Wardle et al. 2015). Wildfires occur commonly in the study region, ignited by lightning strikes during summer thunderstorms (Greenville et al. 2009; Letnic \& Dickman 2006). The most recent occurred over the summer of 2011/2012, with the majority of study grids on Ethabuka Reserve being patchily burned (Greenville 2015; Verhoeven et al. 2020).

\section{Camera deployment}

To investigate activity patterns of lycosids across the dune system and in relation to different environmental conditions, 24 Reconyx PC800 Hyperfire ${ }^{\mathrm{TM}}$ cameras (Reconyx, Inc., Holmen, WI, USA) were established in burned and unburned areas, as well as on dune crests and dune bases in the adjacent interdune swale (Figure 1). Cameras were deployed for 98 days, with each camera positioned $0.5 \mathrm{~m}$ above the sand surface on metal posts set $20 \mathrm{~m}$ apart along four $100 \mathrm{~m}$ long transects running south-east to north-west (consistent with the prevailing dune direction).

Additionally, 12 cameras were orientated at $45^{\circ}$ to incorporate a greater field of view while the other 12 cameras were orientated vertically to increase the likelihood of capturing and identifying lycosids and other invertebrates (Collett \& Fisher 2017). Cameras were deployed from July to October 2016.

Camera settings included both time-lapse and motion-triggered images, with motion-trigger capturing single images in rapid-succession (i.e., no delay between trigger events) and sensitivity set to high to maximize detections. In time-lapse a single image was taken every 5 minutes from 19:00 h to 7:00 h (i.e., from dusk to dawn). Time-lapse was employed to increase captures of invertebrates as well as allowing for a controlled level of sampling effort across cameras, sites and time (Hobbs \& Brehme 2017). Time-lapse was not set to operate by day, in part to conserve battery life, but largely because previous research has shown desert lycosids to be nocturnal, 
148

149

150

151

152

153

154

155

156

157

158

159

160

161

162

163

164

165

166

167

168

169

170

171

172

173

174

175

176

177

178

179

180

181

182

183

184

185

186

187

188

189

190 constraining their activity to relatively cool nights, and relying on burrows to retreat from the heat of the day (Estrada 2008; Framenau 2015). Pilot observations in this study and extended periods working in the study system during the day (e.g., a minimum of $85 \mathrm{~h}$ in targeted ground searches in 2016 and 2017) also confirmed zero lycosid activity by day (CRD unpub. data). Our nocturnal camera settings precluded captures of day-active invertebrates, such as some orthopterans, but diurnal invertebrates were not the main focus of our investigations.

Each photo was tagged with the following details: habitat (burned or unburned), location (crest or swale), position (angled or vertical), camera ID number and, if present, the fauna species and identification confidence level (possible, probable or definite). Only images with high confidence (definite and probable) in identification were used in analyses. Lycosids (two species of Lycosa; Potter et al. 2018) were distinguished from other ground-dwelling spiders such as prowling spiders (Family Miturgidae) by the raised carapace in images and rounded shape of the prosoma (Figure 2). As there are no site-specific identification keys, lycosids were identified to the genus Lycosa using a field guide for spiders of Australia (Whyte and Anderson 2017). Additionally, voucher specimens collected for this study are currently awaiting formal taxonomic resolution (R. Raven, Queensland Museum, pers. comm.). All tags were written to the EXIF data of each file using the multi-format graphics program XnView MP v 0.83 (Gougelet 2016).

\section{Spotlight surveys}

To assess the efficacy of remote-sensing cameras in detecting and revealing activity patterns of lycosids, spotlighting surveys were also undertaken in October 2016 to provide data against which camera activity data could be compared. Spotlighting involved surveying for a total of 10 minutes every hour between 19:30 h (dusk) and 05:30 h (dawn) along a $100 \mathrm{~m}$ transect. Lycosid eyeshine was detected using a Fenix TK35 (960 lumens) hand-held spotlight (Robinson \& Thomson 2016). Lycosids were identified by their distinctive raised carapace and unique eye size and arrangement, which consists of four large posterior eyes that form a square on the carapace and four small anterior eyes that form a single row (Framenau et al. 2014). In comparison, other common ground-dwelling spiders such as prowling spiders (Miturgidae) and ground-spiders (Gnaphosidae) have eight small eyes arranged in two rows of four (Framenau et al. 2014). The number of lycosids observed in each 10-minute survey were tallied. Spotlighting was repeated over three nights (33 surveys in total), following the same $100 \mathrm{~m}$ transect each time for consistency and to reduce bias towards open areas where walking was more straightforward and spiders more easily detected (Figure 1).

\section{Statistical analyses}

The command line package 'exiftool' was used to extract EXIF data from each image and write it to an Excel file. Image time stamps were examined to determine independence, with photographs likely to be of the same individual removed (i.e., those less than 30 mins apart).

In initial analyses, to determine the general activity patterns of lycosids across the dune system, a species detection map was generated using the package 'camtrapR' $\mathrm{v}$ 2.0.3 in R v 4.0.2.

Following this, general lycosid diel activity was ascertained from images pooled across all 
191 cameras, and the circular statistics program Oriana v 4.02 (Kovach Computing Services 2013)

192 was used to calculate mean activity times and $95 \%$ confidence intervals. These statistics were

193 also calculated for spotlighting data. No statistical tests could be made between the two

194 distributions (camera and spotlighting), as spotlighting data were grouped into time classes.

195 Consequently, means and confidence intervals (CI) were compared and significance determined

196 if the 95\% confidence intervals did not overlap. In subsequent analyses, to determine if lycosid

197 activity patterns varied under different circumstances, nocturnal activity patterns from cameras in

198 burned and unburned habitats were compared, as were those from dune crests and bases, using

199 the Mardia-Watson-Wheeler Test (Fisher 1993; Mardia 1969; Mardia \& Jupp 2000) in Oriana.

200 Also known as the Uniform Scores Test, this is a non-parametric test for determining whether

201 two or more circular distributions are identical (Fisher 1993; Mardia \& Jupp 2000; Tasdan \&

202 Yeniay 2014).

203

204

\section{Results}

205 Overall activity

206 Overall, 479,210 images were taken during the study period. Processing took around $100 \mathrm{~h}$ with

207 about $1.6 \%$ of images comprising fauna, including 2,356 images of 7 invertebrate taxa made

208 with high identification confidence (Table 1; Figure 3). There were an additional 2,747 raw

209 images with an additional 7 taxa identified, but confidence in identification was lower.

210 Invertebrates were mainly captured in time-lapse imagery or otherwise in the background of

211 images triggered by vertebrate species; i.e., invertebrates did not trigger motion capture. There

212 were 155 records of lycosids from camera images and 352 lycosids were recorded during

213 spotlighting surveys. Spotlighting data showed lycosids to be active throughout the night, with

214 mean activity of 00:19 h (95 \% CI: 23:58-00:40 h; Figure 4). In comparison, camera data

215 revealed a mean activity time of 23:09 h (95 \% CI: 22:35-23:42 h; Figure 4).

216

217 Environmental influences

218 Greater numbers of invertebrates were recorded on dune crests compared to dune bases, and in

219 unburned compared to burned habitats (Table 1). Additionally, more invertebrates were captured

220 on angled cameras (1516 images) than on vertically oriented cameras (840 images). With respect

221 to lycosids, more were recorded on cameras angled at $45^{\circ}(n=123)$, while only 32 images of

222 lycosids were captured on cameras positioned vertically. Activity was slightly higher on dune

223 bases, with 87 images compared to 68 records on dune crests. However, the detection map

224 revealed that activity on dune bases was dominated by a single camera (camera 16) which logged

$22565.5 \%$ of lycosid records in this habitat (Figure 5). More lycosids were detected in unburned

226 habitats than in burned habitats (102 and 53 records respectively). No difference was detected in

227 diel activity patterns between dune crests and dune bases ( $\mathrm{W}=2.61, \mathrm{p}=0.27$, Figure 6$)$, with the

228 mean activity on dune crests occurring at 23:34 h (95\% CI: 21:45-23:22 h) and mean activity on

229 the dune base at 23:37 h (95\% CI: 22:52-00:23 h). Similarly, no significant difference was

230 detected in the diel patterns of lycosids in burned and unburned habitats $(\mathrm{W}=2.34, \mathrm{p}=0.31$,

231 Figure 7), with mean activity at 23:53 h (95 \% CI: 22:47-00:58 h) for burned habitat and 22:49 h

232 (95 \% CI: 22:11-23:27 h) for unburned habitats. 


\section{Discussion}

235 The results we gathered confirm the value of camera traps in revealing activity patterns of desert-

236 dwelling lycosids. Despite capturing lycosids only using the time-lapse setting, sufficient images

237 were obtained to permit detailed analyses of lycosid temporal and spatial activity across the

238 landscape. Additionally, other invertebrate taxa were confidently identified in over 2,300 images.

239 We first examine the context of these results before discussing the limitations of the study and

240 future directions. Overall, camera traps appear to have considerable utility as a tool for ecological

241 investigations and longer-term monitoring of invertebrates.

242

243 Diel activity patterns

244 Lycosids were found in camera images to be most active 9 minutes after 23:00 h. Despite the

245 mean activity time from spotlighting occurring at a similar time as trends from camera data

246 (about an hour later, at 19 minutes past midnight), there was a clear distinction in the spread of

247 activity times between these two survey techniques. Although there are minor fluctuations in

248 activity, in general spotlighting revealed lycosids to be active right through the night. In contrast,

249 camera data showed a distinct peak in activity just after dusk (19:00-21:00), followed by lower

250 activity during the remainder of the night. A peak in activity just after dusk was also observed in

251 unburned habitat and dune bases, while greater spread in activity throughout the night was

252 observed in burned habitats and on dune crests.

253

254 This pattern is also contrary to our hypothesis that predicted lycosids to be less active near dawn

255 and dusk in open habitats, such as dune crests and burned areas, as this is when the risk of

256 predation is higher (Geiser 1994; Kortner \& Geiser 2011; Potter et al 2018). However, twice the

257 number of lycosids were recorded in unburned habitats with considerable ground cover compared

258 to burned habitats, which suggests that predation may still be driving activity patterns but on a

259 spatial scale rather than a temporal one. A key result of fire is reduced vegetation cover,

260 particularly a reduction in spinifex which is the dominant vegetation in the study region, and

261 which is highly flammable (Greenville et al. 2009). Lycosids have been found previously to

262 prefer microhabitats with less bare ground and more spinifex cover, as it provides a valuable

263 refuge from predators, such as the lesser hairy-footed dunnart (Potter et al. 2018). This preference

264 for areas of greater vegetation cover is also consistent with the notion of intraguild predation,

265 whereby intense competition can lead to subordinate species varying their activity to reduce

266 encounter rates with dominant competitors (Schoener 1974; Palomares et al. 1999). In general,

267 victims tend to exhibit spatial avoidance before displaying temporal partitioning (Schoener 1974;

268 Polis et al. 1989). Conversely, lycosids may be more active in unburned areas as there is greater

269 availability of prey, as more beetles, grasshoppers and other spiders were recorded in unburned

270 areas. Alternatively, it may be a combination of these two dynamics: predators and prey, that

271 drive these spatial trends.

272

273 Advantages of camera traps 
274 In addition to providing information on lycosid activity, camera traps offered a cost-effective, 275 non-invasive tool to survey other invertebrate taxa. For instance, seven taxa were confidently

276 recorded, with an additional seven taxa detected but identified with lower confidence, thus

277 demonstrating the potential utility of cameras as a tool for gauging invertebrate diversity,

278 occupancy or species richness. Camera set-up could be targeted towards greater detection of

279 invertebrates or form an additional component of vertebrate camera surveys, thus providing a

280 more comprehensive and efficient survey technique.

281

282 Detections, or capture rates, could be increased by using camera stations baited with food or scent 283 lures. However, the use of an attractant largely depends on the research project or questions in 284 focus. For instance, although captures of more cryptic or rare species can be increased, baiting

285

286

287

288

289

290

291

292

293

294

295

296

297

298

299

300

301

302

303

304

305

306

307

308

309

310

311

312

313

314

can also modify behaviour and species interactions; i.e., some individuals can become 'traphappy’ while others may subsequently avoid the area (Gerber et al. 2012; Mills et al. 2019).

Additionally, the activity patterns revealed may be artificial, as a lure can often bring animals into an area they may not otherwise frequent, or at different time periods (du Preez et al 2014; Gerber et al. 2012; Mills et al. 2019). Capture rates can be improved passively by extending the survey duration or by placing cameras in areas where species are more likely to be active (e.g., near burrows, along or around logs or debris), or where there is evidence of activity such as in the vicinity of tracks, scats, animals pads or burrows.

Cameras may also be able to detect certain life history traits. In particular, and although not observed during this study, the well-known phenomenon of lycosids transporting their offspring on their body would be discernable from camera images. If there were enough records of this event, differences in reproductive cycles in various habitats or between desert boom and bust periods could be explored. Invertebrate size could also be examined if a ruler is positioned within the camera field of view (Collett \& Fisher 2017). Cameras with video capability could also be employed to investigate foraging behaviour, burrow use or speed.

\section{Limitations}

Spotlighting is the technique of searching for nocturnal animals by using a beam of light to detect an animal's reflected eye shine (Robinson \& Thomson 2016), and has become an accepted standard for surveying populations of arboreal and ground-dwelling fauna, notably vertebrates (e.g., Catling et al. 1997; Engeman \& Vice 2001; Wilmott et al. 2019). Despite being a wellestablished technique, spotlighting is not always successful and factors such as dense vegetation, poor weather conditions (rain, fog), and the nature of the fauna species being targeted (e.g., cryptic, poor eye shine), can decrease the capacity for detections (Catling et al. 1997). Additionally, compared to cameras, spotlighting can be more disruptive to animal behaviour (Robinson \& Thomson 2016), is more labour-intensive, and yields results for single time-periods only. However, the successful use of spotlighting in this study was largely due to the open habitats of the Simpson Desert, the exceptionally bright eye shine of lycosids (Robinson \& Thomson 2016), the combination of 'search and pursuit' and 'sit and move' foraging tactics

PeerJ reviewing PDF | (2020:06:50300:2:0:NEW 8 Dec 2020) 
315 exhibited by individual lycosids (T. Potter pers obs.), as well as the high number of transect

316 surveys completed (33 in total).

317

318 Although cameras are non-invasive, cost-effective and provide continuous data over extended 319 periods of time, the greatest drawback in terms of this study related to the trigger mechanism.

320 Most cameras use a passive infrared (PIR) sensor or heat-in-motion, which detects the presence 321 of an animal when movement or a temperature differential occurs (Meek et al. 2015; Rovero et 322 al. 2013; Swann \& Perkins 2014). Generally, Reconyx ${ }^{\mathrm{TM}}$ cameras (cameras used in this study) 323 will be unreliable if the body temperature of an individual is within $5^{\circ} \mathrm{C}$ of the ambient

324

325

326

327

328

329

330

331

332

333

334

335

336

337

338

339

340

341

342

343

344

345

346

347

348

349

350

351

352

353

354

355

356 temperature (Welbourne 2014). Therefore, animals that have a smaller heat signature, such as ectotherms whose body temperatures seldom fluctuate more than $3{ }^{\circ} \mathrm{C}$ from their surroundings, or smaller bodied organisms, are less likely to trigger the camera (Glen et al. 2013; Harlow et al. 2010; Tobler et al. 2008). Consequently, lycosids were captured only in time-lapse photos. The need for time-lapse imagery meant that a huge number of images was obtained which then had to be sorted and individually tagged. This was an arduous, time-consuming process, with $98.4 \%$ of images containing no fauna. Due to the high number of images, the potential for human error to overlook or mis-identify images was also relatively high. One way to address this problem may be to employ automated identification software, that even at its most basic, removes false-triggers or images that are devoid of fauna (Hobbs \& Brehme 2017; Swinnen et al. 2014). Nonetheless, this process is still fraught with challenges including lack of training data, accounting for environmental factors, such as wind and clouds that generate shifting light conditions and vegetation movement, and an accuracy level that is high enough to detect smaller invertebrates, as opposed to larger, more obvious mammals, birds or reptiles (Hobbs \& Brehme 2017; Swinnen et al. 2014). Consequently, the use of this particular technology is still in the early development stages. However, this study shows that remote cameras can be successfully used to survey some arthropod groups, and thus we hope it drives the collection of more images that could be used as training data for automatic methods.

Another option to improve detectability and efficiency is to reconsider the camera technology, namely the trigger mechanism (Meek \& Pittet 2014; Rovero et al. 2013). Hobbs' Active Light Trigger (HALT) is a tool that has been demonstrated to improve the detectability of small animals (Hobbs \& Brehme 2017). This technology uses a $3 \mathrm{~mm}$ near-infrared (NIR) optical beam that is positioned above an angled threshold which deflects falling leaves and reduces the buildup of debris (Hobbs \& Brehme 2017). The HALT system has demonstrated almost perfect detection probability for small mammals, reptiles, amphibians and large invertebrates regardless of body size or temperature, and functioned satisfactorily in a field setting (Hobbs \& Brehme 2017). It was able to detect slow moving species but not those travelling at speed $\left(\geq 1 \mathrm{~ms}^{-1}\right)$, and falling debris intercepting the optical beam was a cause of false triggers (Hobbs \& Brehme 2017). In another study where the utility of cameras to sample arthropods was compared to pitfall trapping, fallen debris was also found to lower arthropod detectability (Collett \& Fisher 2017). This may pose a more serious limitation on the efficacy of camera traps in heavily vegetated habitats, such as forests, heathlands or tall grasslands. Moreover, it presents a larger barrier for

PeerJ reviewing PDF | (2020:06:50300:2:0:NEW 8 Dec 2020) 
357

358 359

360

361

362

363

364

365

366

367

368

369

370

371

372

373

374

375

376

377

378

379

380

381

382

383

384

385

386

387

388

389

390

391

392

393

394

395

396

397

398

accurate artificial recognition software, in contrast to desert environments where there is greater contrast between invertebrates and the relatively uniform sand background.

Another downside of the HALT system or using a structure such as a drift fence is that they rely on fauna passing along a narrow trail or pathway, and therefore would not be as practical in open habitats such as areas of bare sand. Fauna may also be less inclined to pass up and over the artificial threshold of the HALT system, although the use of a lure or bait may overcome this issue. Finally, the HALT camera battery lasts only one to two weeks (Hobbs \& Brehme 2017). An improved battery operating system may be required, such as greater battery capacity or solar charging, so that a longer monitoring period could be achieved. Reduction in the frequency of images to every 15 minutes may reduce the number of images or extend the sampling timeframe without decreasing the effectiveness of cameras (Collett \& Fisher 2017).

\section{Future directions}

Investigation into the efficacy of camera traps as a tool for uncovering the diel and spatial activity patterns of arthropods presents a significant case for the importance of technological advances in ecology and for gaining a deeper understanding of the biology of understudied organisms. Despite the limitations discussed above, a relatively long-term dataset was gathered, i.e., over a 3-month period rather than direct observations from a discrete time period, such as from a single field trip. If camera technology continues to improve (e.g., the HALT system, automated identification), the application of cameras as a cost-effective, non-invasive tool to study invertebrates, particularly those of conservation interest, would be invaluable. It would permit detailed research into general invertebrate behaviour and biology, as well as enable a greater understanding of the role of invertebrates in terrestrial ecosystems. It would also enable insight into trophic interactions and community-level processes, help inform us as to how invertebrates may be impacted by environmental fluctuations such as climate change and, more broadly, could be applied in the study of landscape health and function, as invertebrates are often used as indicators of habitat restoration and rehabilitation (Fagan et al. 2010; Lenhard \& Witter 1977; Orabi et al. 2010). There could also be economic benefits as awareness of invertebrate crop pest activity may result in more targeted treatments, for example, native predator abatement (Kuusk \& Ekbom 2012; Kuusk et al. 2008; Lavandero et al. 2004; von Berg et al. 2012).

\section{Conclusions}

Cameras with time-lapse settings have considerable utility as a tool for revealing the diel and spatial activity patterns of arthropods and for broader ecological investigations and long-term monitoring of invertebrates.

\section{Acknowledgements}


399

400

401

402

403

404

405

406

407

408

409

410

411

412

413

414

415

416

417

418

419

420

421

422

423

424

425

426

427

428

429

430

431

432

433

434

435

436

437

438

439

440

441

442

443

444

445
We acknowledge the Wangkamadla people as the Traditional Owners of Ethabuka Reserve. We recognize and respect the enduring relationship they have with their lands and water, and we pay our respects to Elders past, present and future. We thank Bush Heritage Australia, in particular Alex Kutt and Matt and Amanda Warr, for allowing access to the study site, Bobby Tamayo for his valuable logistical assistance in the field, Glenda Wardle for helpful discussion, the many volunteers who assisted with data collection, and Larissa Potter and Graeme Finlayson for an earlier review of the draft manuscript.

\section{References}

Agha M, Batter T, Bolas EC, Collins AC, Gomes da Rocha D, Monteza-Moreno CM, PrecklerQuisquater S, and Sollmann R. 2018. A review of wildlife camera trapping trends across Africa. African Journal of Ecology 56:694-701. 10.1111/aje.12565

Black SH, Shepard M, and Allen MM. 2001. Endangered invertebrates: The case for greater attention to invertebrate conservation. University of Michigan, School of Natural Resources. p 41.

Bluett R, and Cosentino B. 2013. Estimating occupancy of Trachemys scripta and Chrysemys picta with time-lapse cameras and basking rafts: A pilot study in Illinois, USA. Illinois State Academy of Science Transactions 106:15-21.

Callan SK, Majer JD, Edwards K, and Moro D. 2011. Documenting the terrestrial invertebrate fauna of Barrow Island, Western Australia. Australian Journal of Entomology 50:323343. 10.1111/j.1440-6055.2011.00818.x

Catling PC, Burt RJ, and Kooyman R. 1997. A Comparison of techniques used in a survey of the ground-dwelling and arboreal mammals in forests in north-eastern New South Wales. Wildlife Research 24:417-432. 10.1071/WR96073

Claridge AW, Mifsud G, Dawson J, and Saxon MJ. 2004. Use of infrared digital cameras to investigate aspects of the social behaviour of cryptic species. Wildlife Research 31:645. 10.1071/WR03072

Collett RA, and Fisher DO. 2017. Time-lapse camera trapping as an alternative to pitfall trapping for estimating activity of leaf litter arthropods. Ecology and Evolution 7:7527-7533. 10.1002/ece3.3275

Coulson S, Hodkinson I, Strathdee A, Bale J, Block W, Worland M, and Webb N. 1993. Simulated climate change: the interaction between vegetation type and microhabitat temperatures at Ny Ålesund, Svalbard. Polar Biology 13:67-70. 10.1007/BF00236585

De Bondi N, White JG, Stevens M, and Cooke R. 2010. Comparison of the effectiveness of camera trapping and live trapping for sampling terrestrial small-mammal communities. Wildlife Research 37:456-465. 10.1071/WR10046

du Preez BD, Loveridge AJ, and Macdonald DW. 2014. To bait or not to bait: A comparison of camera-trapping methods for estimating leopard Panthera pardus density. Biological Conservation 176:153-61. 10.1016/j.biocon.2014.05.021

Dickman CR, Greenville AC, Beh C-L, Tamayo B, and Wardle GM. 2010. Social organization and movements of desert rodents during population "booms" and "busts" in central Australia. Journal of Mammalogy 91:798-810. 10.1644/09-MAMM-S-205.1

Diete R, Meek PD, Dickman CR, Lisle A, and Leung LK-P. 2017. Diel activity patterns of northern Australian small mammals: variation, fixity, and plasticity. Journal of Mammalogy 98:848-857. 10.1093/jmammal/gyx003 
446

447

448

449

450

451

452

453

454

455

456

457

458

459

460

461

462

463

464

465

466

467

468

469

470

471

472

473

474

475

476

477

478

479

480

481

482

483

484

485

486

487

488

489

490

491

492

Ellwood M, D. F. , and Foster W, A. . 2004. Doubling the estimate of invertebrate biomass in a rainforest canopy. Nature 429:549. 10.1038/nature02560

Engeman R, and Vice D. 2001. A direct comparison of trapping and spotlight searches for capturing brown tree snakes on Guam. Pacific Conservation Biology 7:4-8. 10.1071/PC010004

Estrada AP. 2008. Dietary selectivity of the lesser hairy-footed dunnart, Sminthopsis youngsoni, in the Simpson Desert of Central Australia: the importance of spiders. Masters of Applied Science (Wildlife Health and Population Management) Masters. University of Sydney.

Fagan KC, Pywell RF, Bullock JM, and Marrs RH. 2010. Are ants useful indicators of restoration success in temperate grasslands? Restoration Ecology 18:373-379. 10.1111/j.1526100X.2008.00452.x

Fisher DO, and Dickman CR. 1993a. Body size-prey size relationships in insectivorous marsupials: tests of three hypotheses. Ecology 74:1871-1883. 10.2307/1939944

Fisher DO, and Dickman CR. 1993b. Diets of insectivorous marsupials in arid Australia: selection for prey type, size or hardness? Journal of Arid Environments 25:397-410. doi.org/10.1006/jare.1993.1072

Fisher N. 1993. Statistical analysis of circular data. Cambridge, UK: Cambridge University Press.

Framenau VW, Baehr BC, and Zborowski P. 2014. A Guide to the Spiders of Australia. Reed New Holland Publishers Pty Ltd, Sydney.

Framenau VW. 2015 Review of the Australian wolf spider genus Venator (Araneae, Lycosidae). Zootaxa 4013: 541-55

Freckman DW, Blackburn TH, Brussaard L, Patricia H, Palmer MA, and Paul VRS. 1997. Linking biodiversity and ecosystem functioning of soils and sediments. Ambio 26:556562.

Geiser F. 1994. Hibernation and daily torpor in marsupials: a review. Australian Journal of Zoology 42:1-16. 0.1071/ZO9940001

Gerber BD, Karpanty SM, and Kelly MJ. 2012. Evaluating the potential biases in carnivore capture-recapture stud- ies associated with the use of lure and varying density estimation techniques using photographic sampling data of the Malagasy civet. Population Ecology 54:43-54. 10.1007/ s10144-011-0276-3

Gist CS, and Crossley DA. 1973. Method for quantifying pitfall trapping. Environmental Entomology Oct:951-952.

Glen AS, Cockburn S, Nichols M, Ekanayake J, and Warburton B. 2013. Optimising camera traps for monitoring small mammals. PLoS ONE 8:e67940.

Gobbi M, Barragán Á, Brambilla M, Moreno E, Pruna W, and Moret P. 2018. Hand searching versus pitfall trapping: how to assess biodiversity of ground beetles (Coleoptera: Carabidae) in high altitude equatorial Andes? Journal of Insect Conservation 22:533-543. 10.1007/s10841-018-0082-8

Gougelet P-e. 2016. XnView MP. 0.83 ed. France: Gougelet, Pierre-e.

Gowan C, and Vernes K. 2014. Population estimates of an endangered rock-wallaby (Petrogale penicillata) using time-lapse photography from camera traps. In: Meek PD, Fleming P, Ballard G-A, Banks PB, Claridge A, Sanderson J, and Swann D, eds. Camera trapping in wildlife management and research. Vic: CSIRO Publishing, 61-68.

Greenville AC. 2015. The role of ecological interactions: how intrinsic and extrinsic factors shape the spatio-temporal dynamics of populations Doctor of Philosophy. The University of Sydney.

Peer] reviewing PDF | (2020:06:50300:2:0:NEW 8 Dec 2020) 
493

494

495

496

497

498

499

500

501

502

503

504

505

506

507

508

509

510

511

512

513

514

515

516

517

518

519

520

521

522

523

524

525

526

527

528

529

530

531

532

533

534

535

536

537

538

539

540

Greenville AC, Dickman CR, Wardle GM, and Letnic M. 2009. The fire history of an arid grassland: the influence of antecedent rainfall and ENSO. International Journal of Wildland Fire 18:631-639. 10.1071/WF08093

Greenville AC, Wardle GM, Nguyen V, and Dickman CR. 2016. Population dynamics of desert mammals: similarities and contrasts within a multispecies assemblage. Ecosphere 7:e01343. 10.1002/ecs2.1343

Greenville AC, Wardle GM, Tamayo B, and Dickman CR. 2014. Bottom-up and top-down processes interact to modify intraguild interactions in resource-pulse environments. Oecologia 175:1349-1358. 10.1007/s00442-014-2977-8

Harley DKP, Holland GJ, Hradsky BA, and Antrobus JS. 2014. The use of camera traps to detect arboreal mammals: lessons from targeted surveys for the cryptic Leadbeater's possum (Gymnobelidius leadbeateri). In: Meek PD, Fleming P, Ballard G-A, Banks PB, Claridge $\mathrm{A}$, Sanderson J, and Swann D, eds. Camera trapping in wildlife management and research. Vic: CSIRO Publishing, 233-242.

Harlow HJ, Purwandana D, Jessop TS, and Phillips JA. 2010. Size-related differences in the thermoregulatory habits of free-ranging Komodo dragons. International Journal of Zoology 2010. 10.1155/2010/921371

Heavener S, Carthey A, and Banks PB. 2014. Competitive naivete between a highly successful invader and a functionally similar native species. Oecologia 175:73-84. 10.1007/s00442013-2874-6

Henschel JR. 1998. Dune spiders of the Negev Desert with notes on Cerbalus psammodes (Heteropodidae). Israel Journal of Zoology 44:243-251.

Henschel JR. 2002. Long-distance wandering and mating by the dancing white lady spider (Leucorchestris arenicola) (Araneae, Sparassidae) across Namib Dunes. The Journal of Arachnology 30:321-330. 10.1636/0161-8202(2002)030[0321:LDWAMB]2.0.CO;2

Hobbs M, and Brehme C. 2017. An improved camera trap for amphibians, reptiles, small mammals, and large invertebrates. PLoS ONE 12:e0185026.

10.1371/journal.pone.0185026

Körtner G, and Geiser F. 2011. Activity and torpor in two sympatric Australian desert marsupials. Journal of Zoology 283:249-256. 10.1111/j.1469-7998.2010.00766.x

Kovach Computing Services. 2013. Oriana. 4.02 ed. Anglesey, Wales: Kovach Computing Services, Inc. .

Kuusk A-K, and Ekbom B. 2012. Feeding habits of lycosid spiders in field habitats. Journal of Pest Science 85:253-260. 10.1007/s10340-012-0431-4

Kuusk AK, Cassel-Lundhagen A, Kvarnheden A, and Ekbom B. 2008. Tracking aphid predation by lycosid spiders in spring-sown cereals using PCR-based gut-content analysis. Basic and Applied Ecology 9:718-725. 10.1016/j.baae.2007.08.012

Kwok ABC, Wardle GM, Greenville AC, and Dickman CR. 2016. Long-term patterns of invertebrate abundance and relationships to environmental factors in arid Australia. Austral Ecology 41:480-491. 10.1111/aec.12334

Lavandero B, Wratten S, Hagler J, and Jervis M. 2004. The need for effective marking and tracking techniques for monitoring the movements of insect predators and parasitoids. International Journal of Pest Management 50:147-151. 10.1080/09670870410001731853

Lenhard SC, and Witter JA. 1977. Insects as biological indicators of environmental change. Bulletin of the Entomological Society of America 23:191-193. 10.1093/besa/23.3.191

Letnic M, and Dickman CR. 2006. Boom means bust: interactions between the El Niño/Southern Oscillation (ENSO), rainfall and the processes threatening mammal species in arid Australia. Biodiversity and Conservation 15:3847-3880. 10.1007/s10531-005-0601-2

Peer] reviewing PDF | (2020:06:50300:2:0:NEW 8 Dec 2020) 
541

542

543

544

545

546

547

548

549

550

551

552

553

554

555

556

557

558

559

560

561

562

563

564

565

566

567

568

569

570

571

572

573

574

575

576

577

578

579

580

581

582

583

584

585

586

587

588

589

Lortie CJ, Amber B, and Anya R. 2012. From birds to bees: applying video observation techniques to invertebrate pollinators. Journal of Pollination Ecology 6:125-128.

Mardia KV. 1969. On Wheeler and Watson's Two-Sample Test on a circle. Sankhyā: The Indian Journal of Statistics, Series A (1961-2002) 31:177-190.

Mardia KV, and Jupp P. 2000. Directional statistics. Chichester: Wiley.

McCollough MA. 1997. Conservation of invertebrates in Maine and New England: perspectives and prognoses. Northeastern Naturalist 4:261-278. 10.2307/3858611

Meek PD, Ballard G-A, Vernes K, and Fleming PJS. 2015. The history of wildlife camera trapping as a survey tool in Australia. Australian Mammalogy 37:1-12. 10.1071/AM14021

Meek PD, and Pittet A. 2014. A review of the ultimate camera trap for wildlife research. In: Meek PD, Fleming P, Ballard G-A, Banks PB, Claridge A, Sanderson J, and Swann D, eds. Camera trapping in wildlife management and research. Vic: CSIRO Publishing, 101109.

Meek PD, Zewe F, and Falzon G. 2012. Temporal activity patterns of the swamp rat (Rattus lutreolus) and other rodents in north-eastern New South Wales, Australia. Australian Mammalogy 34:223-233. 10.1071/AM11032

Mills D, Fattebert J, Hunter L, and Slotow R. 2019. Maximising camera trap data: using attractants to improve detection of elusive species in multi-species surveys. PLOS ONE 14(5): e0216447. 10.1371/journal. pone.0216447

Nelson JL, Scroggie MP, and Belcher CA. 2014. Developing a camera trap survey protocol to detect a rare marsupial carnivore, the spotted-tailed quoll (Dasyurus maculatus). In: Meek PD, Fleming P, Ballard G-A, Banks PB, Claridge A, Sanderson J, and Swann D, eds. Camera trapping in wildlife management and research. Vic: CSIRO Publishing, 271-279.

Nørgaard T, Henschel J, and Wehner R. 2006. The night-time temporal window of locomotor activity in the Namib Desert long-distance wandering spider, Leucorchestris arenicola. Journal of Comparative Physiology A 192:365-372. 10.1007/s00359-005-0072-7

Nyffeler M, and Benz G. 1987. Spiders in natural pest control: A review 1. Journal of Applied Entomology 103:321-339. 10.1111/j.1439-0418.1987.tb00992.x

Oberprieler S, Andersen A, and Braby M. 2019. Invertebrate by-catch from vertebrate pitfall traps can be useful for documenting patterns of invertebrate diversity. Journal of Insect Conservation 23:547-554. 10.1007/s10841-019-00143-z

Orabi G, Moir ML, and Majer JD. 2010. Assessing the success of mine restoration using Hemiptera as indicators. Australian Journal of Zoology 58:243-249. 10.1071/ZO10033

Pagnucco KS, Paszkowski CA, and Scrimgeour GJ. 2011. Using cameras to monitor tunnel use by long-toed salamanders (Ambystoma macrodactylum): an informative, cost-efficient technique. Herpetological Conservation and Biology 6:277-286.

Palomares F, Caro TM, Associate Editors: John AB, and Robert DH. 1999. Interspecific killing among mammalian carnivores. The American Naturalist 153:492-508. 10.1086/303189

Peters E, and McFadden J. 2010. Influence of seasonality and vegetation type on suburban microclimates. Urban Ecosystems 13:443-460. 10.1007/s11252-010-0128-5

Polis GA, Myers CA, and Holt RD. 1989 The ecology and evolution of intraguild predation: potential competitors that eat each other. Annual Review of Ecology and Systematics 20: 297-330. 10.1146/annurev.es.20.110189.001501

Ponder WF, and Lunney D. 1999. The other 99\% : the conservation and biodiversity of invertebrates. Sydney, NSW: Royal Zoological Society of New South Wales.

Popic TJ, Davila YC, and Wardle GM. 2013. Evaluation of common methods for sampling invertebrate pollinator assemblages: net Sampling out-perform pan traps. PLOS ONE 8:e66665. 10.1371/journal.pone.0066665

Peer) reviewing PDF | (2020:06:50300:2:0:NEW 8 Dec 2020) 
590

591

592

593

594

595

596

597

598

599

600

601

602

603

604

605

606

607

608

609

610

611

612

613

614

615

616

617

618

619

620

621

622

623

624

625

626

627

628

629

630

631

632

633

634

635

636

637

638

Potter LC. 2017. Camera trap constraints in focus: assessing detectability and identification of small mammals in camera trap studies Bachelor of Science (Advanced) Honours. Charles Darwin University.

Potter LC, Brady CJ, and Murphy BP. 2019. Accuracy of identifications of mammal species from camera trap images: A northern Australian case study. Austral Ecology 44:473-483. 10.1111/aec.12681

Potter TI, Greenville AC, and Dickman CR. 2017a. Availability of invertebrate prey for microcarnivores, Version 1. ÆKOS Data Portal, rights owned by University of Sydney. 10.4227/05/5a17a9ab8652b

Potter TI, Greenville AC, and Dickman CR. 2017b. Temporal activity of wolf spiders and dunnarts in the Simpson Desert, Version 1. ÆKOS Data Portal, rights owned by University of Sydney. 10.4227/05/5a167887d329a

Potter TI, Greenville AC, and Dickman CR. 2017c. Direct observations of foraging wolf spiders and dunnarts, Version 1. ÆKOS Data Portal, rights owned by University of Sydney. 10.4227/05/5a151e727fb2f

Potter TI, Greenville AC, and Dickman CR. 2017d. Microhabitat selection by wolf spiders and dunnarts, Version 1. ÆKOS Data Portal, rights owned by University of Sydney. 10.4227/05/5a1f43d3542e5

Potter TI, Greenville AC, and Dickman CR. 2018. Assessing the potential for intraguild predation among taxonomically disparate micro-carnivores: marsupials and arthropods. Royal Society Open Science 5:171872. 10.1098/rsos.171872

Punzo F. 2003. Observations on the natural history and ecology of the wolf spider Hogna carolinensis (Walckenaer) (Araneae, Lycosidae) in the northern Chihuahuan Desert. Bulletin of the British Arachnological Society 12:399-404.

Purdie R. 1984. Land systems of the Simpson Desert Region. Natural Resources Series no 2. Melbourne: CSIRO Division of Water and Land Resources.

Robinson M, and Thomson B. 2016. Australian Wildlife After Dark: CSIRO Publishing.

Rovero F, Zimmermann F, Berzi D, and Meek PD. 2013. "Which camera trap type and how many do I need?" A review of camera features and study designs for a range of wildlife research applications. Hystrix, the Italian Journal of Mammalogy 24:1148-1156. 10.4404/ hystrix-24.2-6316

Rowcliffe JM, Carbone C, Kays R, Kranstauber B, and Jansen PA. 2014. Density estimation using camera trap surveys: the random encounter model. In: Meek PD, Fleming P, Ballard G-A, Banks PB, Claridge A, Sanderson J, and Swann D, eds. Camera trapping in wildlife management and research. Vic: CSIRO Publishing, 317-323.

Russell-Smith A, Ritchie JM, and Collins NM. 1987. The surface-active spider fauna of arid bushland in Kora Reserve, Kenya. Bulletin of the British Arachnological Society 7:171174.

Schoener TW. 1974. Resource partitioning in ecological communities. Science 185:27-39. 10.1126/science.185.4145.27

Southwood TRE, and Henderson PA. 2000. Ecological Methods, 3rd Edition. Oxford, UK: Blackwell Science.

Swann D, and Perkins N. 2014. Camera trapping for animal monitoring and management: a review of applications. In: Meek PD, Fleming P, Ballard G-A, Banks PB, Claridge A, Sanderson J, and Swann D, eds. Camera trapping in wildlife management and research. Vic: CSIRO Publishing, 3-11.

Swinnen KR, Reijniers J, Breno M, and Leirs H. 2014. A novel method to reduce time investment when processing videos from camera trap studies. PLoS ONE 9:e98881. 10.1371/journal.pone.0098881

Peer) reviewing PDF | (2020:06:50300:2:0:NEW 8 Dec 2020) 
639

640

641

642

643

644

645

646

647

648

649

650

651

652

653

654

655

656

657

658

659

660

661

662

663

664

665

666

667

668

669

670

671

672

673

674

675
Tasdan F, and Yeniay O. 2014. Power study of circular anova test against nonparametric alternatives. Hacettepe Journal of Mathematics and Statistics 43:97-115.

Tobler MW, Carrillo-Percastegui SE, Leite Pitman R, Mares R, and Powell G. 2008. An evaluation of camera traps for inventorying large-and medium-sized terrestrial rainforest mammals. Animal Conservation 11:169-178. 10.1111/j.1469-1795.2008.00169.x

Verhoeven EM, Murray BR, Dickman CR, Wardle GM, and Greenville AC. 2020. Fire and rain are one: extreme rainfall events predict wildfire extent in an arid grassland. International Journal of Wildland Fire 29:702-711. 10.1071/wf19087

Vernes K, Smith M, and Jarman PJ. 2014. A novel camera-based approach to understanding the foraging behaviour of mycophagous mammals. In: Meek PD, Fleming P, Ballard G-A, Banks PB, Claridge A, Sanderson J, and Swann D, eds. Camera trapping in wildlife management and research. Vic: CSIRO Publishing, 215-224.

von Berg K, Traugott M, and Scheu S. 2012. Scavenging and active predation in generalist predators: A mesocosm study employing DNA-based gut content analysis. Pedobiologia 55:1-5. 10.1016/j.pedobi.2011.07.001

Wardle GM, Greenville AC, Frank ASK, Tischler M, Emery NJ, and Dickman CR. 2015. Ecosystem risk assessment on Georgina gidgee woodlands in central Australia. Austral Ecology 40:444-459. 10.1111/aec.12265

Welbourne D. 2014. Using camera traps to survey diurnal terrestrial reptiles: a proof of concept. In: Meek PD, Fleming P, Ballard G-A, Banks PB, Claridge A, Sanderson J, and Swann D, eds. Camera trapping in wildlife management and research. Vic: CSIRO Publishing, 225232.

Welbourne D, Claridge A, Paull D, and Ford F. 2020. Camera-traps are a cost-effective method for surveying terrestrial squamates: A comparison with artificial refuges and pitfall traps. PLoS ONE 15:e0226913. 10.1371/journal.pone.0226913

Whyte R, and Anderson G. 2017. A field guide to spiders of Australia. Melbourne: CSIRO Publishing.

Wilmott L, Cullen D, Madani G, Krogh M, and Madden K. 2019. Are koalas detected more effectively by systematic spotlighting or diurnal searches? Australian Mammalogy 41:157-160. 10.1071/AM18006

Woinarski JCZ, Andersen AN, Churchill TB, and Ash AJ. 2002. Response of ant and terrestrial spider assemblages to pastoral and military land use, and to landscape position, in a tropical savanna woodland in northern Australia. Austral Ecology 27:324-333. 10.1046/j.1442-9993.2002.01183.x

Wong MKL, Guénard B, and Lewis OJ. 2019. Trait-based ecology of terrestrial arthropods. Biological Reviews 94:999-1022. 10.1111/brv.12488 


\section{Table $\mathbf{1}$ (on next page)}

Invertebrate taxa captured on remote-sensing cameras in different habitats in the Simpson Desert.

Table 1. Invertebrate taxa captured on remote-sensing cameras in different habitats in the Simpson Desert. Data are raw numbers of images for all taxa except lycosids, which are independent records. Raw images are used as independence between records is difficult to establish for some taxa (e.g. ants and moths). Only images with high confidence in identification ('definite') are presented here. 
1

2 Table 1. Invertebrate taxa captured on remote-sensing cameras in different habitats in the Simpson Desert. Data

3 are raw numbers of images for all taxa except lycosids, which are independent records. Raw images are used as

4 independence between records is difficult to establish for some taxa (e.g. ants and moths). Only images with high

5 confidence in identification ('definite') are presented here.

\begin{tabular}{|cccccc|}
\hline Taxa & No. of images & Dune Crest & Dune Base & Burned & Unburned \\
\hline Ant (Hymenoptera) & 1215 & 624 & 591 & 501 & 714 \\
\hline Beetle (Coleoptera) & 769 & 565 & 204 & 214 & 555 \\
\hline Grasshopper (Orthoptera) & 5 & 3 & 2 & 1 & 4 \\
\hline Lycosid (Lycosidae) & 155 & 20 & 95 & 30 & 85 \\
\hline Moth (Lepidoptera) & 69 & 55 & 14 & 40 & 29 \\
\hline Scorpion (Scorpiones) & 1 & 1 & 0 & 1 & 0 \\
\hline Other spiders (Arachnidae) & 27 & 22 & 5 & 1 & 26 \\
\hline Total & $\mathbf{2 3 5 6}$ & $\mathbf{1 3 5 8}$ & $\mathbf{9 9 8}$ & $\mathbf{8 4 1}$ & $\mathbf{1 5 1 5}$ \\
\hline
\end{tabular}

6 
Figure 1

Arrangement of remote-sensing cameras near Main Camp, Simpson Desert, Queensland.

Figure 1. Arrangement of remote-sensing cameras near Main Camp, Simpson Desert, Queensland. Twenty-four cameras were deployed, half in recently burned (summer of 2011/2012) and half in unburned habitat. Within these two habitats, 6 cameras were situated on the dune crest and 6 in the swale. Two camera positions were tested: a) angled at $45^{\circ}$ (orange squares, $n=12$ ) and b) vertically (white squares, $n=12$ ). The purple line indicates the transect followed during spider spotlighting surveys.

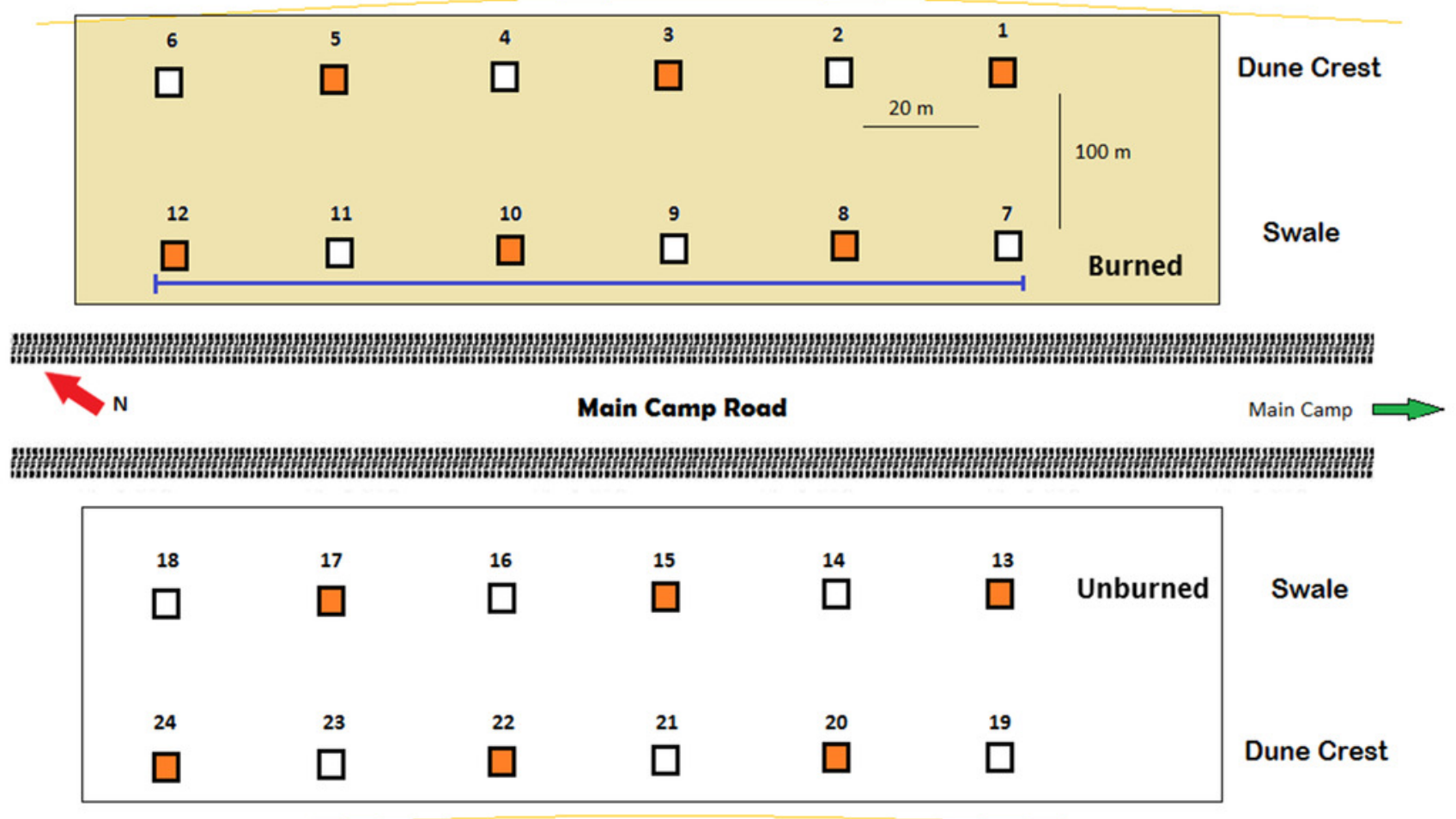




\section{Figure 2}

Photos of wolf spiders (Lycosidae: Lycosa spp.) taken using remote-sensing cameras deployed at Main Camp, Simpson Desert, Queensland between July and October 2016.

Figure 2. Photos of wolf spiders (Lycosidae: Lycosa spp.) taken using remote-sensing cameras deployed at Main Camp, Simpson Desert, Queensland between July and October 2016. Two camera positions were employed to maximise capture success of the study species, i.e. $45^{\circ}$ angle $(\mathbf{a} \& \mathbf{b})$ or vertical (c). Lycosids were distinguished from other grounddwelling spiders (e.g., prowling spiders: Miturgidae) by the raised carapace (evident in image a) and shape of their prosoma, which is more rounded compared to miturgids.
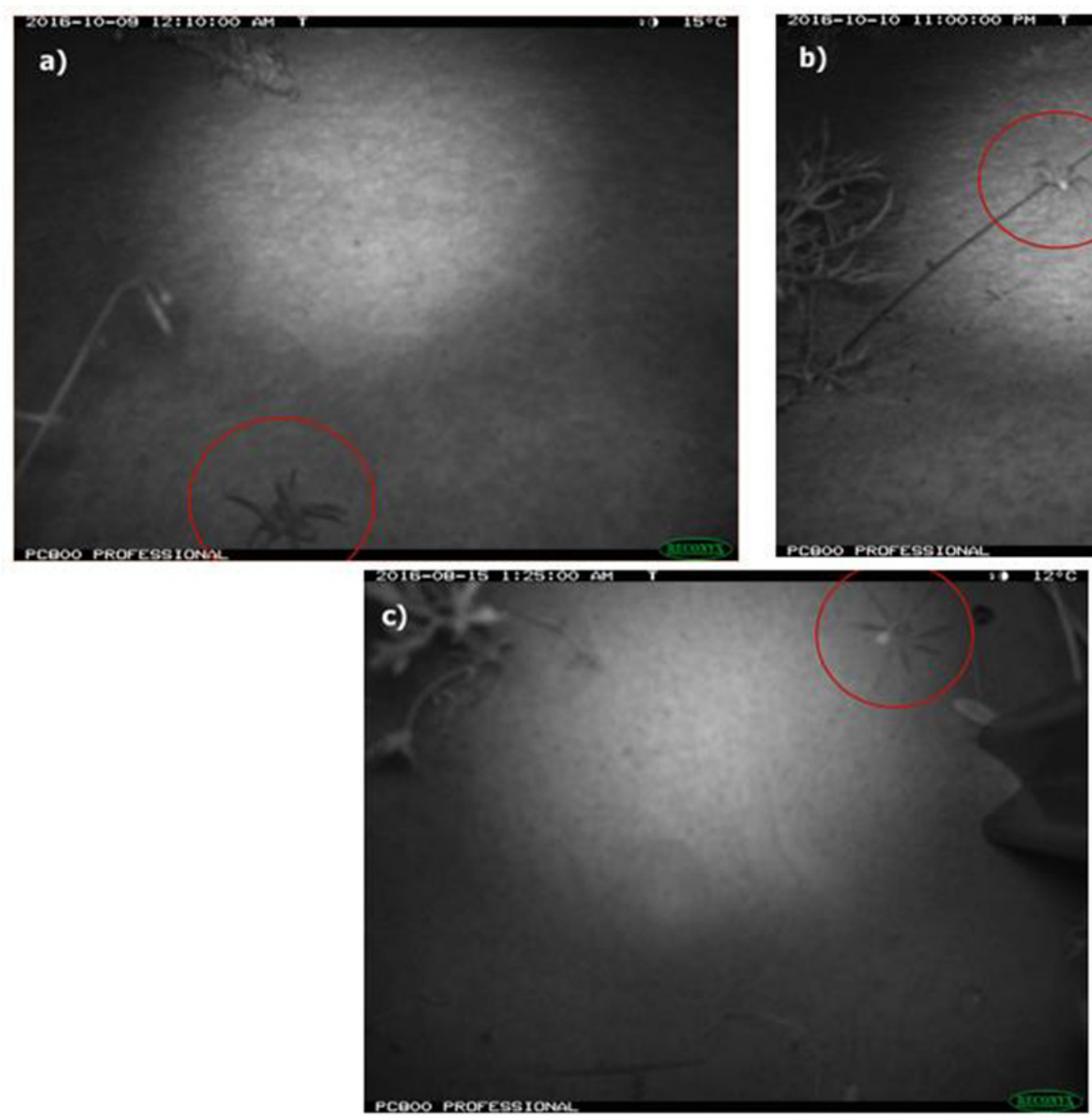


\section{Figure 3}

Photos of invertebrate taxa from remote-sensing cameras

Figure 3. Invertebrate taxa captured in time-lapse images from cameras deployed at Main Camp, Simpson Desert, Queensland between July and October 2016: (a) and (b) beetles (Coleoptera), (c) moth (Lepidoptera), and (d) grasshopper (Orthoptera).
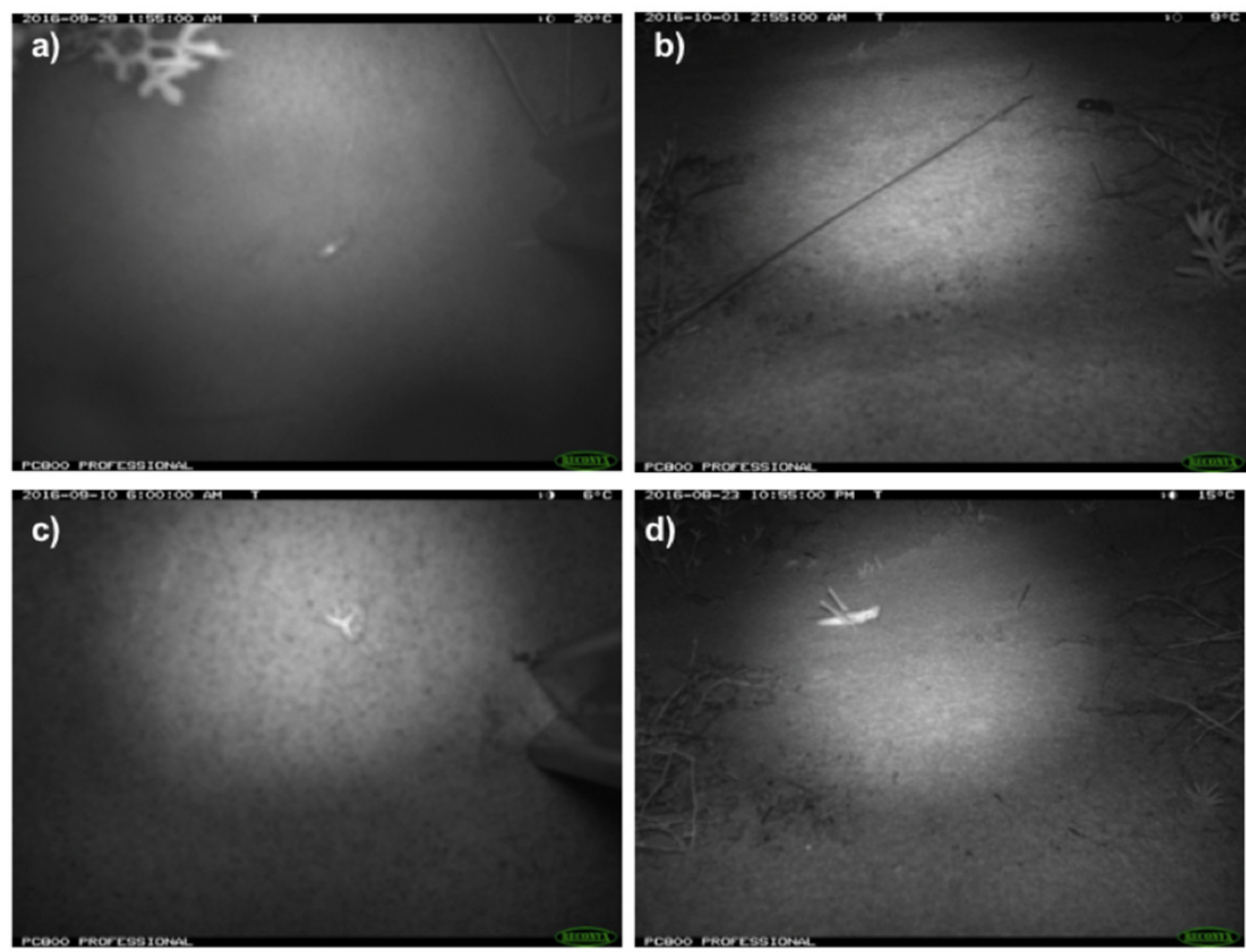

d) 
Figure 4

Diel activity patterns of lycosids from spotlighting and camera data

Figure 4. Diel activity patterns of lycosids based on (a) spotlighting data and (b) data pooled across all cameras at Main Camp, Simpson Desert, Queensland. Activity is the proportion of records aggregated in each hourly period.

a)

0000

0300

2100

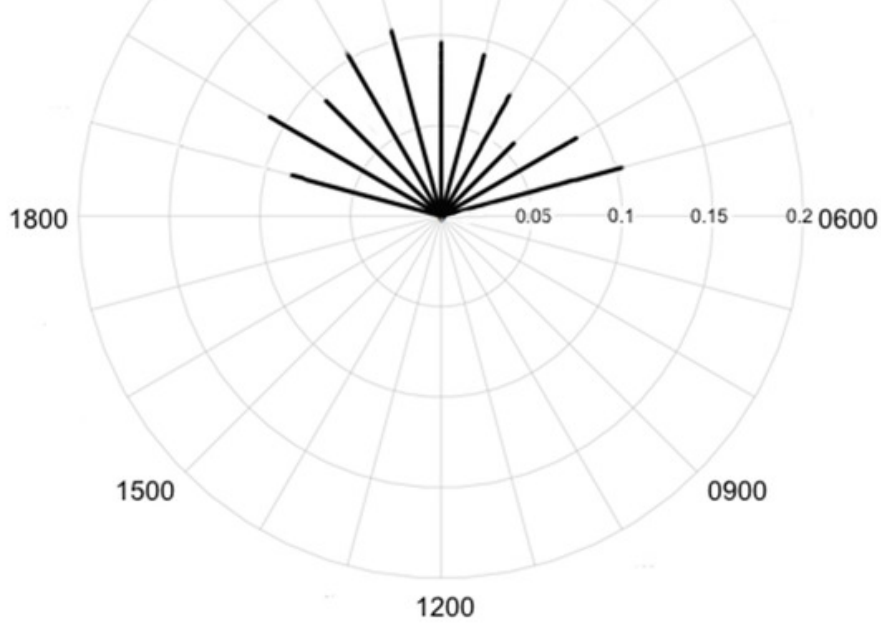

b)

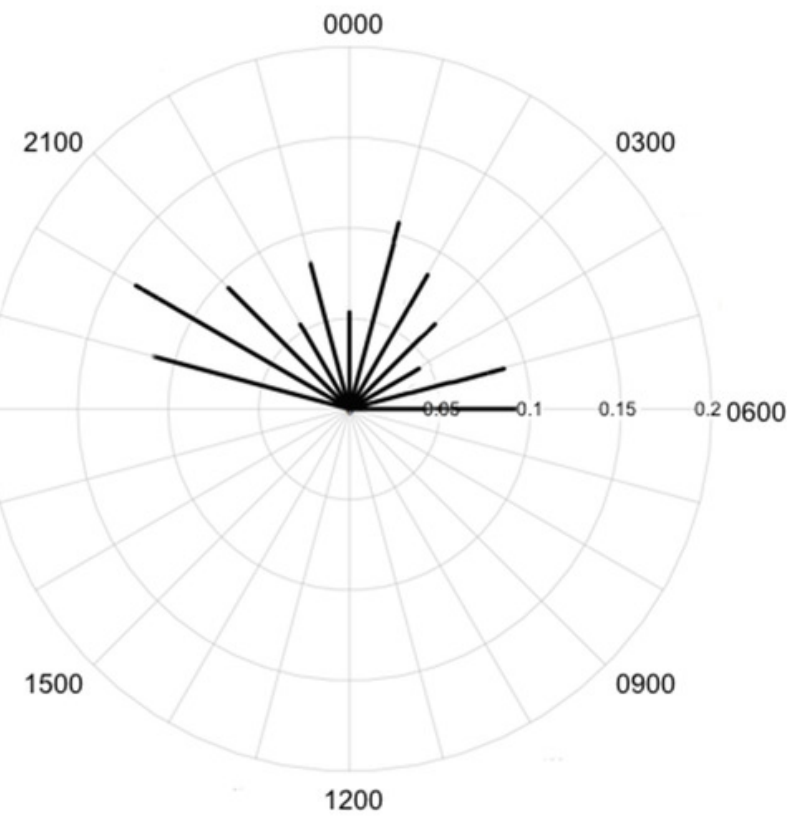


Figure 5

Lycosid detection map generated using camera records.

Figure 5. Lycosid detection map generated using camera records. Camera numbers are indicated in red. Cameras 1 through to 6 and 19 to 24 are positioned on dune crests while 7 to 12 and 13 to 18 are in the interdune swale. Additionally, the first 12 cameras are in burned habitat with the remaining 12 cameras in unburned habitat.
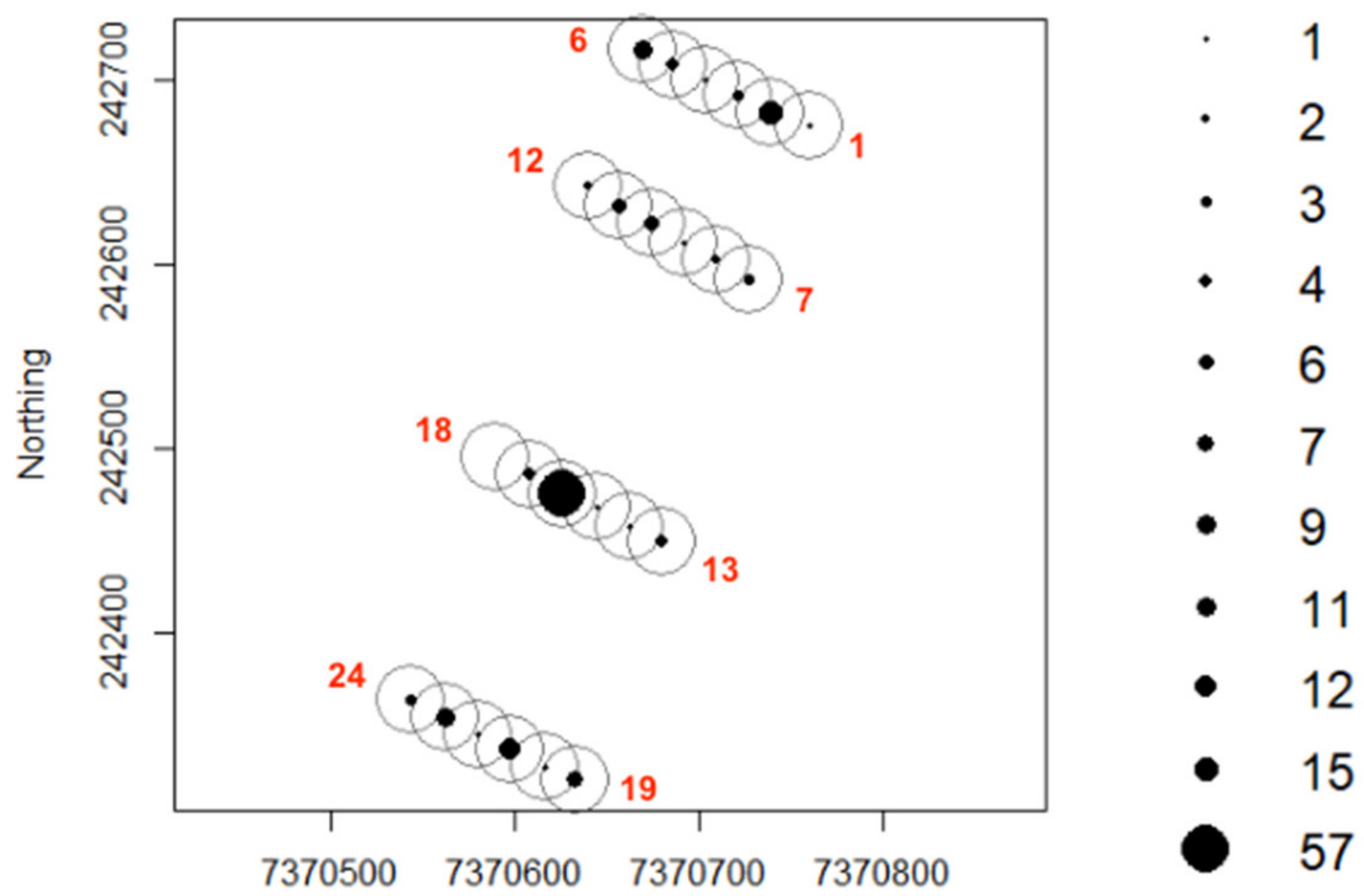

Easting 
Figure 6

Diel activity patterns of lycosids on dune crests and dune bases using data extracted from camera images.

Figure 6. Diel activity patterns of lycosids on (a) dune crests and (b) dune bases using data extracted from camera images deployed at Main Camp, Simpson Desert, Queensland between July and October 2016. Activity is the proportion of records aggregated in each hourly period.

a)

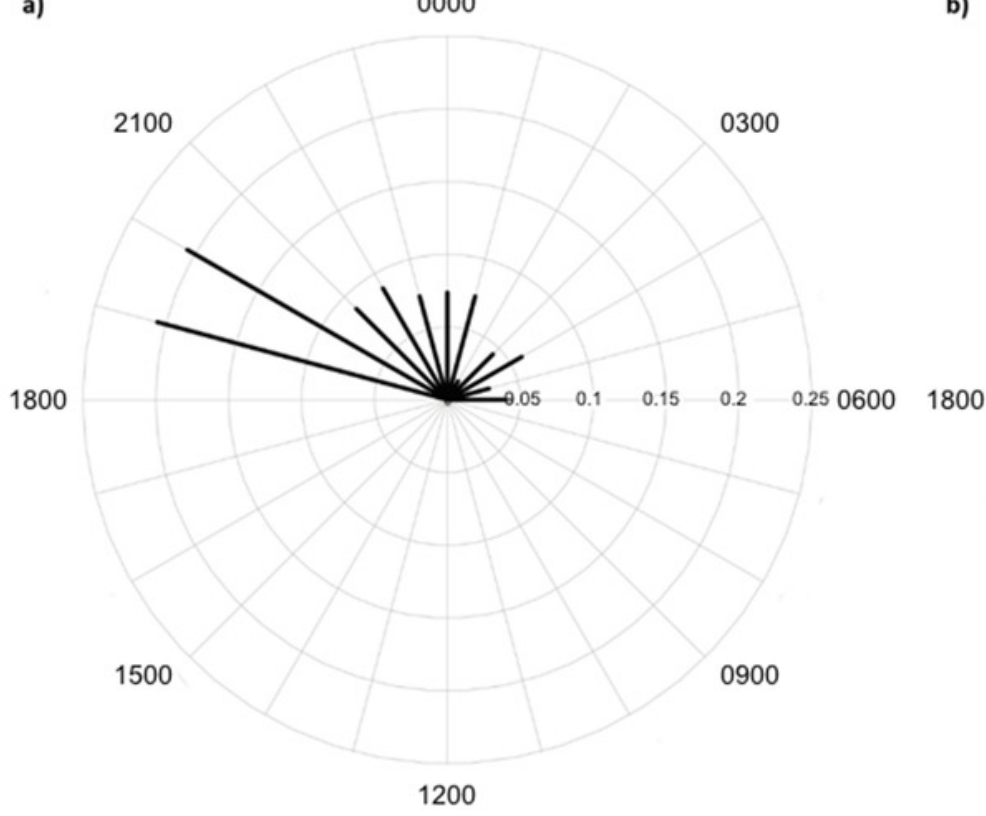

b)

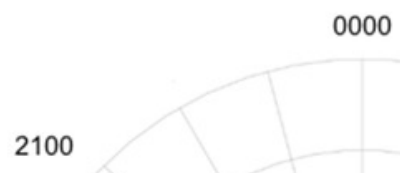

1500

0900

0300

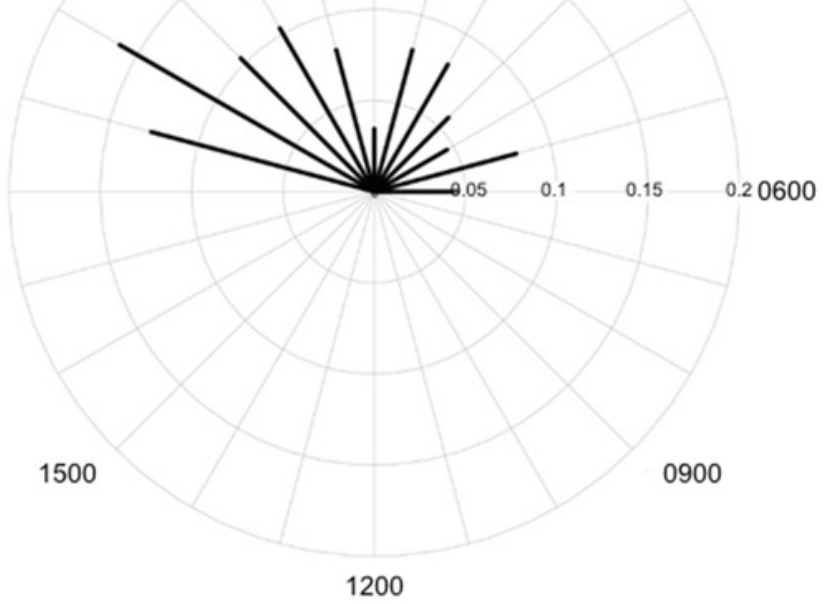




\section{Figure 7}

Diel activity patterns of lycosids in burned and unburned habitats using data extracted from camera images.

Figure 7. Diel activity patterns of lycosids in (a) burned and (b) unburned habitats using data extracted from camera images deployed at Main Camp, Simpson Desert, Queensland between July and October 2016. Activity is the proportion of records aggregated in each hourly period.

a)

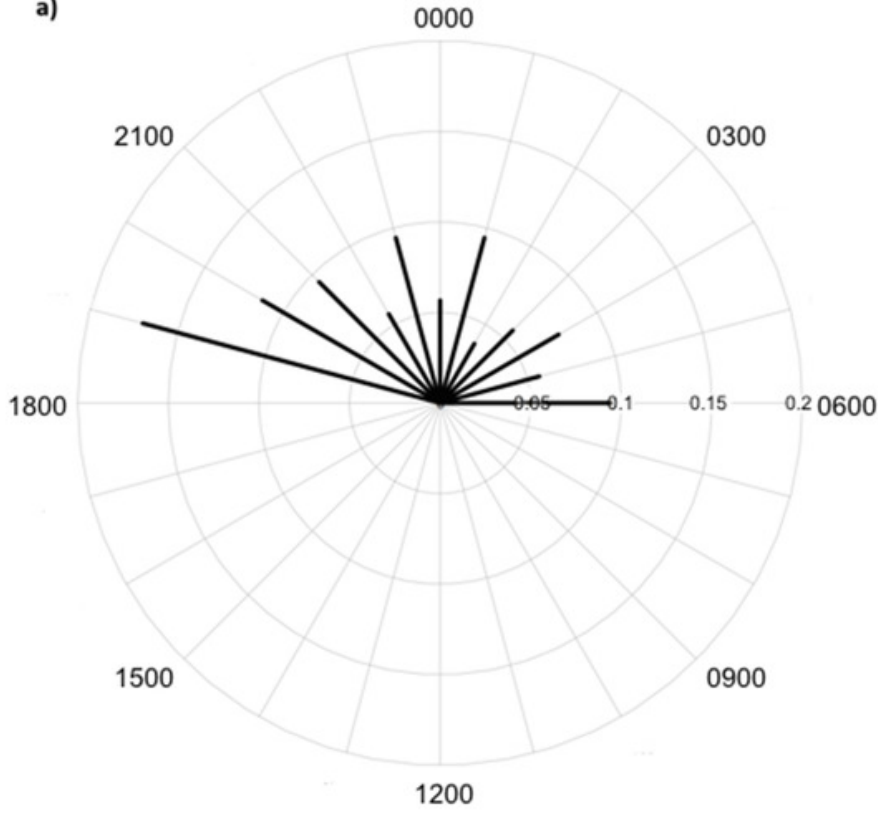

b)

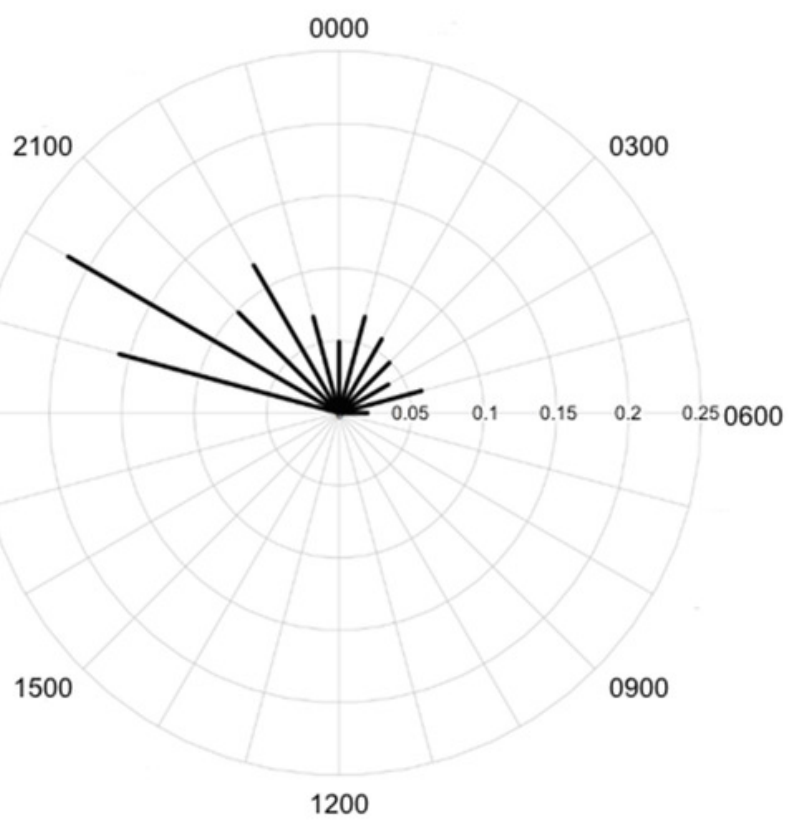

